\title{
DIREITO E ECONOMIA: A CONTRIBUIÇÃO DE ROSA LUXEMBURGO PARA O ESTUDO CRÍTICO DO DIREITO DO IDOSO
}

\author{
Lucas Santos de Almeida ${ }^{1}$ \\ Ana Maria Viola de Sousa ${ }^{2}$
}

\begin{abstract}
Resumo: O presente trabalho insere-se na abrangente temática dos direitos humanos, particularmente sob o diferenciado espectro do direito das minorias, repercutindo sua análise na especificidade consubstanciada pelo direito do idoso. Pretende-se, mediante um estudo interdisciplinar, pautado na teoria crítica do direito, verificar as interações dialéticas entre direito e economia, as quais, conforme soberbamente demonstrado por Rosa Luxemburgo, definem a natureza de ambas as searas, no que pese a particularidade de cada uma delas. Sendo assim, verifica-se que o próprio conceito de pessoa idosa encontra gênese no modus operandi atinente ao sistema econômico vigente, do qual deriva o correspondente ordenamento jurídico regulamentador das relações de produção e de toda sociabilidade.
\end{abstract}

Palavras-chave: Rosa Luxemburgo; Direito: Economia; Direito do Idoso.

\footnotetext{
1 Programa de Mestrado em Direito, Centro Universitário Salesiano de São Paulo, Rua Dom Bosco, n²84, Centro, Lorena, Brasil. E-mail: lucas.s.almeida@uol.com.br.

2 Programa de Mestrado em Direito, Centro Universitário Salesiano de São Paulo, Rua Dom Bosco, n 284, Centro, Lorena, Brasil. E-mail: amvds@uol.com.br.
} 